\title{
Occupational health in Great Britain in 1970
}

\author{
R. S. F. SCHILLING \\ TUC Centenary Institute of Occupational Health \\ London School of Hygiene and Tropical Medicine, London W.C.1
}

In the United Kingdom, Government responsibility for occupational health and safety is shared by at least four departments, the Ministry of Agriculture, Fisheries and Food and the Departments of Trade and Industry, Employment, and Health and Social Security. They report annually on their various activities, the main one being to enforce the Law to protect employed persons from the hazards of their work.

This divided responsibility for occupational health and safety has historical origins. Early in the nineteenth century governments were forced to prevent the exploitation of women and children in factories and mines, and later to protect workers of all ages against the growing hazards of occupational injury and disease. Separate inspectorates for factories and mines and quarries were established, and later in the nineteenth century local authorities were given responsibility for enforcing legislation to protect those employed in workshops. During the present century the mechanization of agriculture and the increasing use of toxic pesticides have made it necessary to introduce laws to protect farm workers. The Agriculture (Poisonous Substances) Act (1952) and the Safety, Health and Welfare Provisions Act (1956) are enforced by officers of the Ministry of Agriculture, Food and Fisheries. In spite of its name this ministry does not report on the health and safety of fishermen. This is done by the Department of Trade and Industry, which in its most recent report (1971a) gives shipping casualties, and the number and causes of death of merchant seamen and fishermen for 1969 .

The Offices, Shops and Railway Premises Act of 1963 , one of the most recent statutes in this field, makes provision for the health, safety, and welfare of about eight million people, that is, about one- third of the working population of the United Kingdom. Its administration is another example of the policy of divided responsibility. The Act has four enforcing authorities: the Factory Inspectorate, the Mines and Quarries Inspectorate, and local and fire authorities. Another important but less well recognized Government responsibility for occupational health and safety stems from its duty to provide social security for the insured population, a duty which now belongs to the Department of Health and Social Security. The data on the benefits and pensions paid for occupational injury and disease provide a means of assessing the extent and severity of hazards and also the burden of general sickness, some of which originates from the failure of industry to observe reasonable standards of care for people at work. The uses made of these data are limited. The latest report for 1970 (Department of Health and Social Security (DHSS), 1971) gives the number of spells of certified incapacity terminated in the 12-month period June 1968 to May 1969 for industrial accidents and prescribed industrial diseases. These totals are sub-divided for males and females under 'causes' and give the estimated average duration of the spells of absence. For the pneumoconioses and related diseases spells beginning in this 12-month period are given elsewhere in the report. No rates are given. The data are not discussed and no comparisons are made with previous years to indicate secular trends.

It might be argued that it is unnecessary for the DHSS to provide such details because this is done in the reports of the Chief Inspectors of Factories, and Mines and Quarries, who cover most of the working population employed in the most hazardous occupations. This, however, is not the case. In 1970 there were 822000 new claims for injury benefit 
among the insured population. Nearly 500000 of these were non-fatal, reportable accidents occurring in workplaces covered by these inspectorates; a further 36000 were new claims for prescribed occupational diseases and the pneumoconioses. Thus there are at least a quarter of a million new industrial injuries and diseases per year, severe enough to cause more than three days' absence from work, which, however, are not subjected to the kind of analysis and investigation required for reportable accidents occurring in workplaces covered by the Factories, and Mines and Quarries Acts. Obviously, it would be impracticable to provide complete cover for all workplaces. More detailed analysis of these injuries, showing what they are, where they occur, and their incidence, would indicate hazardous occupations which should, therefore, be subjected to the type of control required in factories and mines. Deep-sea fishing is a case in point. An inquiry into trawler safety in 1968, following the loss of three trawlers with 58 men, revealed that the accident mortality of fishermen was at least twice that of coal miners. It showed that the figures published by the Registrar General on occupational mortality grossly underestimated the risk because most of the deaths at sea are not taken into account in calculating mortality rates (Committee of Inquiry into Trawler Safety, 1969). Since this inquiry, some measures have been taken to make deep-sea fishing a safer occupation. Nevertheless, the Department of Trade and Industry, in its latest report (see above), gives no accident rates and no figures at all for nonfatal accidents to crews of fishing vessels. There is no published evidence to show the success or failure of new safety measures. By contrast, the annual reports of the Chief Inspectors of Factories (Department of Employment, 1971) and of Mines and Quarries (Department of Trade and Industry, 1971b) give excellent reviews of their Inspectorates' work and the state of health and safety in the workplaces they cover. Data are given in sufficient detail to enable one to assess the extent and severity of occupational hazards in various types of industry. The successes, as well as the failures, are discussed. Such reports must help these Government departments to formulate policies; they must also encourage both management and the technical experts to achieve and maintain higher standards of health and safety in their workplaces.

Mr. Bryan Harvey, the Chief Inspector of Factories, gives encouragement to the construction industry in which the rates for both fatal and severe injuries are substantially lower in 1970 than in 1969. The long-term trend in fatal accident rates in factories (deaths per 100000 persons employed) reveal a quite dramatic fall: 1901-10 17.5; 1929-38 11.6; and 1961-70 4.5. If the rates for 1929-38 are applied to the population at risk in 1961-70, there is a saving in the order of about 5000 lives over the last 10 years compared with the 10 years before the war. This, Mr. Harvey says, is a tribute to those responsible for accident prevention as well as to the technical advances in traumatic surgery. It shows that all the effort and money put into accident prevention by industry, voluntary organizations, and the Factory Inspectorate have been worth while. There are many hazards which cause a good deal of concern, such as those due to the use of inferior steel sections in the construction industry; the continuing occurrence of serious accidents from mobile cranes due to faulty slinging, overturning of the crane, and collapse of the jib; and overexposure to ionizing radiations in industrial radiography. There is still much to be done to control toxic dusts, particularly asbestos, a hazard which, although recognized for many years, has been shown by medical research to be far greater than it was thought to be 20 years ago. However, the extent of the risk having been identified, new and much more stringent regulations have been set and have already led to improvements.

The medical branch of the Factory Inspectorate has made an important contribution to the identification and control of occupational diseases during the twentieth century. In the last 10 years, under the leadership of Dr. Trevor Lloyd Davies, it has become much more active, particularly in its survey and laboratory work. It has made valuable investigations of respiratory disease in foundry and pottery workers, of byssinosis in cotton workers, and of occupational cancer in the rubber, cable making, and asbestos industries. These studies have given a much more precise picture of the extent and severity of these hazards. The medical laboratory has also developed new surveillance techniques, such as a method of screening lead workers which avoids venepuncture, and another for determining urinary fluorides.

The medical inspector's role has always been advisory rather than inspectorial. With the development of laboratory and survey work, it has been detached from the Inspectorate to form a new Medical Services Division which co-ordinates the work of the medical inspectors (now medical advisers), the medical officers of the Industrial Rehabilitation Units, and those in the Government Training Centres. This medical division will still work closely with the Factory Inspectorate. However, in its new role it is poised to take on the functions envisaged in the new Employment Medical Advisory Services Bill. The other inspectorates which cover workplaces such as mines, quarries, and farms do not have the same medical expertise as the Factory Inspectorate to investigate health hazards and give advice. Such medical expertise may not be necessary for the coal mines owned by the National Coal Board, which has its own occupational health service. But 
there are other mines and quarries in which controls are less stringent and where there may be hazards to health which are unidentified and uncontrolled. The same may be said of farms and many other workplaces. This is one of the most serious disparities in the standards of Government service.

The Annual Report of the Chief Inspector of Mines and Quarries is another valuable report giving essential data and discussing both the good and bad trends in accident rates. While both fatal and serious injuries per 100000 man-shifts continue to fall, tub and mine-car haulage accidents have shown a marked increase; $37 \%$ can be attributed to defects in construction, installation, and maintenance, and $42 \%$ to personal factors. Mr. J. W. Calder, the Chief Inspector, criticizes the industry's tendency to employ young persons and older men on supply haulages, whereas this type of work requires experienced men who are properly supervised. The Inspectorate, with the co-operation of the National Coal Board, have tried hard to improve dust suppression. Since 1961 there has been a decline in the proportion of pits attaining approved dust conditions, but strenuous efforts made in 1970 have reversed this trend. In spite of increasing mechanization $81.5 \%$ of nearly 1000 samples taken on the production shift did not exceed the recommended standard, an average of $8 \mathrm{mg}$ of respirable dust per cubic metre of air in the return roadway. At least 700 new cases of pneumoconiosis still occur every year and, as Mr. Calder says, determined efforts are necessary to control the adverse effects of widespread mechanization. There has been a remarkable decline in new cases of other occupational diseases, that is, from 15599 in 1952 to 3153 in 1970. Nystagmus has been virtually wiped out and the 'beats' have fallen from nearly 11000 cases per year to less than 1500 . There may be many reasons for this decline in cases, apart from the shrinking population of miners. The National Coal Board's occupational health service must be given some credit for these successes and for preventing the expected rise in the incidence of pneumoconiosis with increasing mechanization.

The report on safety, health and welfare in agriculture (Ministry of Agriculture, Fisheries and Food, 1971) is thin by comparison with those of the Chief Inspectors of Factories and Mines. It contains no rates for accidents and disease, and 6 of its 18 pages deal with wages on which the Ministry is required to report by virtue of the Agricultural Wages Act 1948. Nevertheless there are examples from the section on safety which illustrate the value of recording and investigation. The overturning farm tractor is the principal single cause of death among farm workers. Thirty-two people were killed as a result of such accidents in both 1968 and 1969, and 26 in 1970. Investigation of overturning accidents in
1970 showed that where safety cabs were fitted no lives were lost. The new regulations for tractor cabs came into force in 1970 and require the fitting of safety frames which should prevent loss of life from this cause. The number of children under 15 killed on farms continues to rise; it was 16 in 1968, 17 in 1969 , and 24 in 1970.

The first example shows how a major hazard has been identified and controlled. The second highlights a serious problem of accidents to children, almost reminiscent of the horrors of child labour in the nineteenth century, which, for two main reasons, the special regulations to protect children on farms have not successfully controlled. That 42 people were convicted in 1970 for breach of these regulations shows that they are not being strictly observed; nor can such regulations guard against every hazard to which a child may be exposed. There is no easy solution. The Ministry is using all available means of publicity through the press, television, sound broadcasting, and films to make it widely known that the farm can be a dangerous playground and workplace for children.

Increasing public awareness is probably the first important step towards achieving better control of occupational hazards. Too many of the $\mathbf{1 5}$ million people at work accept inadequate-and sometimes unnecessarily dangerous and unpleasant-conditions as a matter of course. Good enough facts about the extent and severity of hazards and publicity to make a real impact are lacking.

The division of Government responsibility for health and safety of people at work among several Government departments or even branches of the same department is an almost inevitable consequence of the evolutionary processes which occur in a democracy. Such divisions may even be desirable. A strong case can be made for having separate inspectorates for factories and mines because the nature of their work is quite different, but there are less cogent reasons for having a separate inspectorate for farms. About $88 \%$ of farming accidents have the same basic causes as factory accidents. They occur as a result of falls, falling objects, or exposure to machinery. The remaining $12 \%$, that is, about 700 a year, are caused by animals, mostly horses and other apparently innocuous animals (624), and relatively few by dangerous breeds such as bulls and boars (71). Prevention probably depends more than anything else on training and experience in handling animals, just as training and experience in operating machines and toxic processes are essential for the control of hazards in factories.

The Annual Report by the Secretary of State for Employment (1971) on the work carried out during 1970 under the Offices, Shops and Railway Premises Act 1963 shows that over $90 \%$ of inspections were made by local authorities. Reported accidents are 
given by class of workplace and primary cause, but without any rates for populations at risk. There are no means of knowing the relative accident risks in offices, retail shops, wholesale departments, and warehouses, where nearly $90 \%$ of accidents occur. It seems, from the narrative descriptions, that the Act has been successful in ensuring the health and safety of employees in some workplaces which six years ago had little or no protection. The report suffers by comparison with that of the Chief Inspector of Factories from the same department.

In eastern European countries, the state takes the major responsibility for the promotion of occupational health and safety. In the United Kingdom, promotion depends on the voluntary effort of employers and professional and research organizations. British industry and commerce have developed their own health services because the Government's provision through the National Health Service, the Employment Medical Advisory Service, and its inspectorates is not enough. The British Government, however, has very important responsibilities in spite of these voluntary efforts. It needs to raise and maintain the standards of employers' services and to provide services for workplaces which cannot do so for themselves. It has also the means, through the data it collects on national mortality and morbidity, of providing the intelligence which can lead to the detection and assessment of occupational hazards. It has a major responsibility in pursuing its own research and providing enough funds to enable university departments and others also to do research.

It is evident from reading these six annual reports that some departments do more than fulfil their legal obligations and that others do no more than the minimum required by inadequate statutes. There are workplaces such as hospitals and schools where virtually no cover is given for occupational health and safety. The most urgent needs are to fill the gaps, to make better use of national records on occupa- tional mortality and morbidity which would include record linkage, and to co-ordinate the activities of various Government departments without necessarily having unified responsibility in one department.

There is a strong case for some form of permanent inter-departmental commission to encourage such co-ordination and to review the extent and severity of existing hazards and their causes, and to advise on improvements needed in the identification, assessment, and control of hazards and where further research is needed.

The Government has realized that something needs to be done. In 1970 it set up the Committee of Inquiry on Safety and Health at Work under the chairmanship of Lord Robens. This committee is reviewing provisions already made, considering whether any changes are needed in legislation and the nature and extent of voluntary action, and will make recommendations; its report is imminent. It could be an important landmark in the history of occupational health and safety in Great Britain.

\section{References}

Committee of Inquiry into Trawler Safety (1969). Final Report. Cmnd 4114.

Department of Employment (1971). Annual Report of H.M. Chief Inspector of Factories for 1970. Cmnd 4758.

Department of Health and Social Security (1971). Annual Report for 1970 . Cmnd 4714.

Department of Trade and Industry (1971a). Shipping Casualties and Deaths. Return for 1969.

(1971b). Annual Reports of H.M. Chief Inspector of Mines and Quarries for 1969 and 1970.

Ministry of Agriculture, Fisheries and Food (1971). Annual Report on Safety, Health, Welfare and Wages in Agriculture for 1970.

Secretary of State for Employment (1971). Annual Report on the Offices, Shops and Railway Premises Act for 1970.

(All these reports are published by Her Majesty's Stationery Office, London.)

Received for publication January 12, 1972. 